Revista Aspas

ppgac - USP

Desenhos de Pesquisa

\title{
O TENSIONAMENTO AFETIVO NAS RELAÇÕES ENTRE CORPO E CIDADE ATRAVÉS DO PROGRAMA PERFORMATIVO NO ESPAÇO URBANO
}

\begin{abstract}
THE AFFECTIVE TENSION IN THE RELATIONS BETWEEN BODY AND CITY THROUGH THE PERFORMATIVE PROGRAM IN THE URBAN SPACE
\end{abstract}

\section{LA TENSIÓN AFECTIVA EN LAS RELACIONES ENTRE CUERPO Y CIUDAD A TRAVÉS DEL PROGRAMA PERFORMATIVO EN EL ESPACIO URBANO}

\section{Jéssica Sousa Faria, Marcelo Braga de Carvalho e Sandra Regina Facioli Pestana}

Jéssica Sousa Faria

Graduada no Bacharelado e Licenciatura em Teatro na Universidade Anhembi Morumbi. Projeto de iniciação cientifica concluído em 2019. Área de estudo: Performance e criação.

Orientadores: Dr. Marcelo Braga de Carvalho e Dr. a Sandra

Regina Facioli Pestana. Bolsa de fomento: PIBIC/CNPq 2018/2019. Arte-educadora e atriz.

Marcelo Braga de Carvalho Professor no curso de Teatro na Universidade Anhembi Morumbi e Doutor em Formação do Artista Teatral pela Escola de Comunicações e Artes da USP.

Sandra Regina Facioli Pestana Professora no curso de Teatro na Universidade Anhembi Morumbi e Doutora em Artes pela ECA/USP. 


\section{Resumo}

Este artigo tem como objetivo principal analisar a relação entre espaço urbano e corpo-transeunte através de uma abordagem artística e pedagógica. Sendo assim, este projeto utilizará como ferramenta investigativa o Programa Performativo que, segundo Eleonora Fabião, conduz o corpo a experiências que lhe propiciam a criação de relações e circulações afetivas. Para construção da ação do referido programa foram utilizados conceitos da Teoria da Deriva de Guy Debórd e as experiências artísticas e poéticas desenvolvidas por Renato Almeida e Antônio Arantes. O campo de estudo estava circunscrito às imediações da Praça das Artes, localizada no centro histórico da cidade de São Paulo. Este sítio urbano, que contém patrimônios históricos e culturais da cidade, revela-se um campo fértil para a experimentação e investigação das práticas artísticas aqui propostas e, também, disparador para a criação de ações instalativas.

Palavras-chave: Deriva, espaço urbano, práticas artísticas, Vestígio, Programa Performativo.

\section{Abstract}

This article aims to analyze the relations between urban space and body pedestrian through an artistic and pedagogical approach. Therefore, this project will use as a research tool the Performative Program which, according to Eleonora Fabião, leads the body to experiences that enable it to create relationships and affective circulations. In order to establish the action of this program, we used concepts from Guy Debord's Drift Theory and the artistic and poetic experiences developed by Renato Almeida and Antônio Arantes. As a study object, the surroundings of Praça das Artes, located in the historic center of the city of São Paulo. This urban site, which contains historical and cultural heritage of the city, proves to be a fertile area for the experimentation and investigation of the artistic practices proposed, and propellant for the creation of installation actions.

Keywords: Drift, urban space, artistic practices, vestige, Performative Program.

\section{Resumen}

Este artículo tiene como reto principal analizar las relaciones entre el espacio urbano y el cuerpo-peatón por medio de un enfoque artístico y pedagógico. Por consiguiente, este proyecto utilizará el "Programa Performativo" como una herramienta de investigación que, según 
Eleonora Fabião, conduz el cuerpo a experiencias que le permiten crear relaciones y circulaciones afectivas. Para construir la acción de dicho programa, fueron utilizados conceptos de la teoría de la deriva de Guy Debórd y las experiencias artísticas y poéticas desarrolladas por Renato Almeida y Antônio Arantes. Como sitio de estudio, los alrededores de la "Praça das Artes", ubicada en el centro histórico de la ciudad de São Paulo. Este sitio urbano, que contiene gran parte del patrimonio histórico y cultural de la ciudad, demuestra ser un campo fértil para la experimentación e investigación de las prácticas artísticas propuestas aquí y, también, poder desencadenar la creación de acciones de instalación.

Palabras clave: Deriva, espacio urbano, prácticas artísticas, Vestigio, Programa Performativo.

\section{INTRODUÇÃO}

Este artigo, derivado do projeto de iniciação científica da pesquisadora Jéssica Sousa Faria, tem como objetivo principal investigar a relação entre espaço urbano e corpo-transeunte através de uma abordagem artística e pedagógica. As vivências educativas da pesquisadora nos patrimônios históricos e complexos culturais da cidade permitiram a elaboração de experiências performativas no centro de São Paulo. Nestes experimentos, a memória individual era utilizada como dispositivo de mediação entre o transeunte e o espaço urbano. A partir disso, verificou-se a necessidade de investigar e analisar as potencialidades das relações afetivas entre corpo e cidade. Desta forma, este projeto utiliza como ferramenta investigativa o Programa Performativo que, segundo Eleonora Fabião (2013), conduz o corpo a experiências que lhe propiciam a criação de relações e circulações afetivas:

O programa é o enunciado da performance; um conjunto de ações previamente estipuladas, claramente articuladas e conceitualmente polidas a ser realizado pelo artista, pelo público ou por ambos sem ensaio prévio (p. 4).

Para construção da ação do Programa Performativo aplicada nesse estudo, foram utilizados conceitos da Teoria da Deriva de Guy Debórd (2018), 
especialmente a ideia de que quando uma pessoa ou grupo pequeno entregase à deriva, renuncia aos motivos pelos quais se desloca e deixa-se levar pelos encontros e solicitações dos espaços. Utilizou-se também, como referência, as práticas artísticas e os conceitos descritos por Renato Almeida (2017) e Antônio Arantes (1994). Na primeira, o autor explica o caminhar no espaço urbano como atitude política e procedimento poético, o que se dá no encontro entre o corpo e a cidade que habita e este é afetado por esta, vivenciando seus tensionamentos políticos, sociais e econômicos. Na segunda, Arantes (1994) descreve a cidade como espaço comum, mas repleto de limites e fronteiras simbólicas no qual o caminhante atento é um corpo que se arrisca por este território, constrói sentidos e posiciona-se.

As referidas ações e experiências realizadas nesta pesquisa tiveram como foco magno abordar o corpo como campo simbólico de transformação, visando ampliar a sensibilização do indivíduo com relação ao seu entorno e o outro.

\section{2- O CENTRO DE SÃO PAULO COMO ESPAÇO DE PESQUISA}

Ao escolher o centro de São Paulo, mais especificamente o entorno da Praça das Artes, como espaço de investigação foi necessário refletir sobre a conexão entre os habitantes e os lugares que transitam e quais relações sociais, políticas e históricas que influenciam essas conexões.

Construída na Quadra 27 do centro de São Paulo, a Praça das Artes é uma extensão das atividades artísticas e administrativas do Theatro Municipal de São Paulo. O projeto do complexo cultural teve início em 2006 - sendo inaugurado o primeiro módulo em 2012 - e tem como uma das propostas a requalificação do centro urbano e o prolongamento do Vale do Anhangabaú1.

\footnotetext{
1 Fonte: PRAÇA das Artes. In: ENCICLOPÉDIA Itaú Cultural de Arte e Cultura Brasileiras. São Paulo: Itaú Cultural, 2020. Disponível em:<http://enciclopedia.itaucultural.org.br/obra69952/praca-dasartes>
} 
A pesquisadora Jéssica Faria participou de programas de formação do setor educativo ${ }^{2}$ do Theatro Municipal, nos quais a ministrante Prof ${ }^{a}$ Dr. ${ }^{\text {a }}$ Ana Castro, da Faculdade de Arquitetura e Urbanismo USP, apontou os fatores que desencadearam o abandono da área central da cidade, entre os anos 60 e 70. Neste período, o centro experimentava mudanças nos hábitos culturais da capital, não sendo mais o lugar principal de moradia e nem o único ponto a oferecer serviços, sofrendo assim um abandono do poder público. Esta experiência formativa gerou uma importante questão que contribuiu para a análise proposta por este trabalho: como as fronteiras físicas e simbólicas alteram a relação dos nossos corpos com estes espaços?

Ainda em relação ao espaço público, o pesquisador Arantes (1994) discorre sobre a experiência social urbana no centro de São Paulo, em específico na região entre a Praça da Sé e a Praça da República - locais que se aproximam dos escolhidos na pesquisa - e descreve como as relações sociais e afetivas são afetadas pelo planejamento urbano e os sistemas de vigilância e controle. $O$ autor ainda descreve a efemeridade constante trazida pelos transeuntes que cruzam esses territórios com pouca aderência, em contraste tanto com a presença das moradias de pessoas em situação de rua - que constroem ali as paredes invisíveis de suas casas - quanto com os prédios de bancos, lojas do comércio, construções históricas e patrimônios culturais, que também constituem o cenário desta pesquisa por onde "[...] transita-se constantemente, dificilmente se está" (ARANTES, 1994, p. 200).

A partir dessas reflexões foi elaborado um projeto de iniciação científica para analisar como as relações afetivas podem ser investigadas através de dispositivos performativos e instalativos.

\footnotetext{
${ }^{2}$ Estes encontros de palestras estavam inseridos no planejamento de formação dos estagiários do setor Educativo do Theatro Municipal de São Paulo, no qual a pesquisadora integrou como Educadora estagiária entre os anos 2016 e 2019.
} 


\section{3- A EXPERIÊNCIA DA PESQUISADORA NO CENTRO DE SÃO PAULO}

A partir da experiência como arte-educadora no espaço urbano, a pesquisadora pôde identificar os lugares existentes no centro antigo de São Paulo ocupados por diferentes grupos sociais, espaços esses que estão em fricção com a vida na metrópole, impressão essa também corroborada por Arantes:

Penso que os lugares sociais assim construídos não estão simplesmente justapostos uns aos outros como se formassem um grande mosaico. A meu ver, eles se superpõem e, entrecruzandose de modo complexo, formam zonas simbólicas de transição (1994, p. 191).

Entre os anos de 2018 e 2019, a experiência da deriva - que propõe ao transeunte que caminhe pela cidade sem um trajeto ou objetivo definido (DEBORD,1958) - possibilitou a construção de afetividades entre a pesquisadora e os ambientes que ela desejava para cenário desta investigação e também ativou sua percepção crítica sobre a relação entre corpo e espaço, estimulando a construção de um olhar sensível para as relações que existiam naqueles ambientes, como evidencia registro da pesquisadora que segue:

\footnotetext{
$\mathrm{Na}$ calçada estreita e escura existia uma casa

Uma moça costumava jogar cartas sentada no chão, durante as tardes.

Alguns homens que trabalhavam no estacionamento a chamavam por um apelido. Ela olhava para eles, sorria e depois retornava a sua rotina. Dentro do fluxo intenso da rua Crispiniano, me acostumei a vê-la sorrir. Quando notei, por esses dias, que ela não morava mais lá, senti que naquele pedaço onde vivia estava presente a sua ausência.
}

Estas vivências propiciaram a criação de um Programa Performativo, pois demonstraram a potencialidade performativa do caminhar quando esta ação é executada pelo indivíduo sem estar condicionada às obrigações e trajetos cotidianos. 


\section{4- METODOLOGIA E RESULTADOS}

A prática do Programa Performativo ocorreu em um único encontro dividido em duas etapas. Os participantes e a pesquisadora realizaram a leitura de fragmentos dos teóricos citados e, após breve reflexão e preparação, iniciaram a deriva.

Entre o Vale do Anhangabaú e a Praça das Artes foi instalado um espelho, contendo uma pergunta: "O que você faz para sobreviver?". Esta pergunta foi escolhida para a experiência, pois teve sua origem em um Programa Performativo realizado anteriormente pela pesquisadora enquanto membro do setor Educativo do Theatro Municipal de São Paulo.

Para coletar as impressões dos participantes, estes foram orientados a escolher um vestígio durante a Deriva e, após o retorno, a fazer registros através de textos, fotos e desenhos (Figura 1) e, também, escolher uma palavra que sintetizasse a experiência.

A noção de vestígio aplicada a esta investigação parte da leitura de Almeida:

(...) materiais que carreguem alguma forma de comunicação como escrita ou outras formas simbólicas, como desenhos, monumentos, esculturas, ou ainda, podem ter um caráter mais ordinário funcionalmente como ferramentas, utensílios, vestimentas etc. $(2017$, p. 58$)$.

Figura 1: Participantes confeccionando registros.

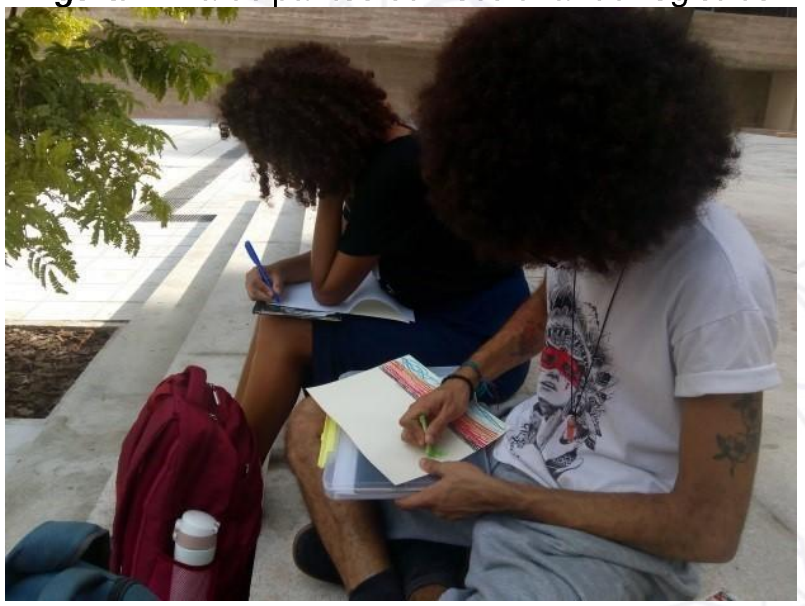

Fonte: Acervo pessoal da pesquisadora

Tais materiais foram analisados pela pesquisadora, a partir das seguintes perguntas norteadoras: Quais os vestígios coletados? Quais 
palavras-síntese foram escolhidas? Tais palavras são representativas de como os corpos se relacionaram com o espaço?

A diversidade das relações afetivas registradas pode ser percebida nos seguintes trechos dos relatos dos participantes:

\begin{abstract}
Estar à deriva não muda só o corpo, muda principalmente o olhar(...). O olhar me fez observar os hábitos intrínsecos a -quasetodos os corpos que circulam na rua em conexão com a rede através dos celulares. A relação do meu corpo dentro desse contexto é de um estudo de quase libertação; não estar condicionado ao celular ou a minha bolsa possibilita essa sensação, chegando ao ponto de eu ter vontade de dormir ao ar livre. Palavrasíntese: Des-olhar. (W.M)
\end{abstract}

A cidade fagocita o indivíduo, e quando estamos num lugar fora desse andar cotidiano, é possível sentir o contraste e fazer com que toda a nossa percepção seja ampliada, pelo simples fato de não termos um prazo para cumprir ou objetivo para alcançar. Palavrasíntese: Centro-Margem. (L.S)

O participante W.M fez o percurso no Vale do Anhangabaú, sendo interessante observar a forma como realizou a deriva - não somente utilizando os pés, mas com outras partes de seu corpo - permitindo relações singulares e extraordinárias (Figura 2). Ao tocar e ser tocado pela cidade, o indivíduo reinventa os usos e intervenções do corpo no espaço-público. A palavrasíntese "Des-olhar" e o relato nos permitem entender de que formas os corpos podem ser afetados pelo espaço urbano e pelo convívio com os outros que compartilham deste mesmo ambiente.

Figura 2: participante W.M interagindo com o Vale do Anhangabaú.

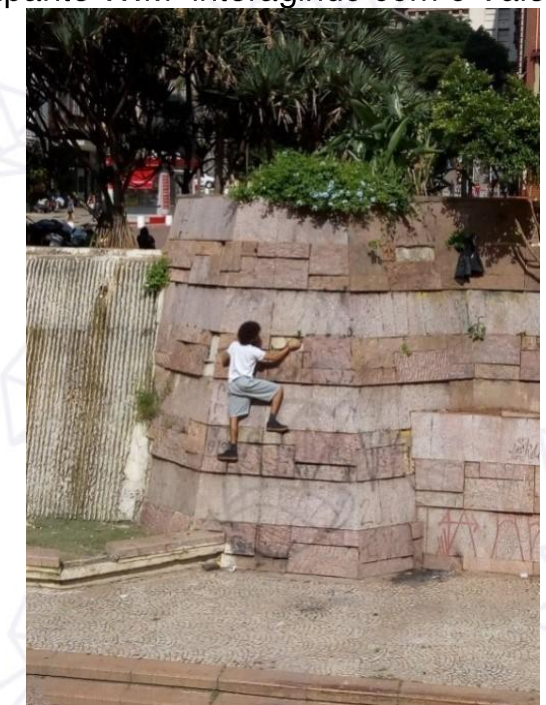

Fonte: Acervo pessoal da pesquisadora. 
A participante L.S. realizou seu percurso próximo à Praça das Artes e do prédio dos Correios (figura 3). Ao analisar a palavra-síntese "CentroMargem" e as imagens produzidas que registram o vestígio (figura 4), nota-se como ambos complementam as percepções dela sobre os limites que existem na cidade. Tais palavras e vestígios escolhidos são representativos.

Figura 3: participante L.S iniciando a Deriva no entorno da Praça das Artes.

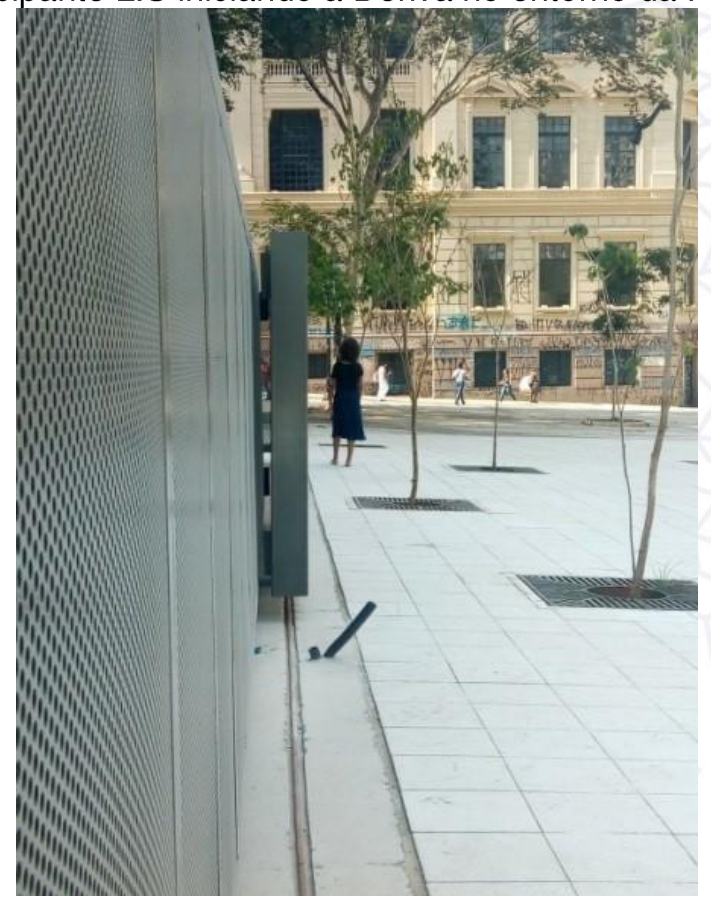

Fonte: Acervo pessoal da pesquisadora.

Figura 4: vestígio escolhido pela participante L.S.: as grades.

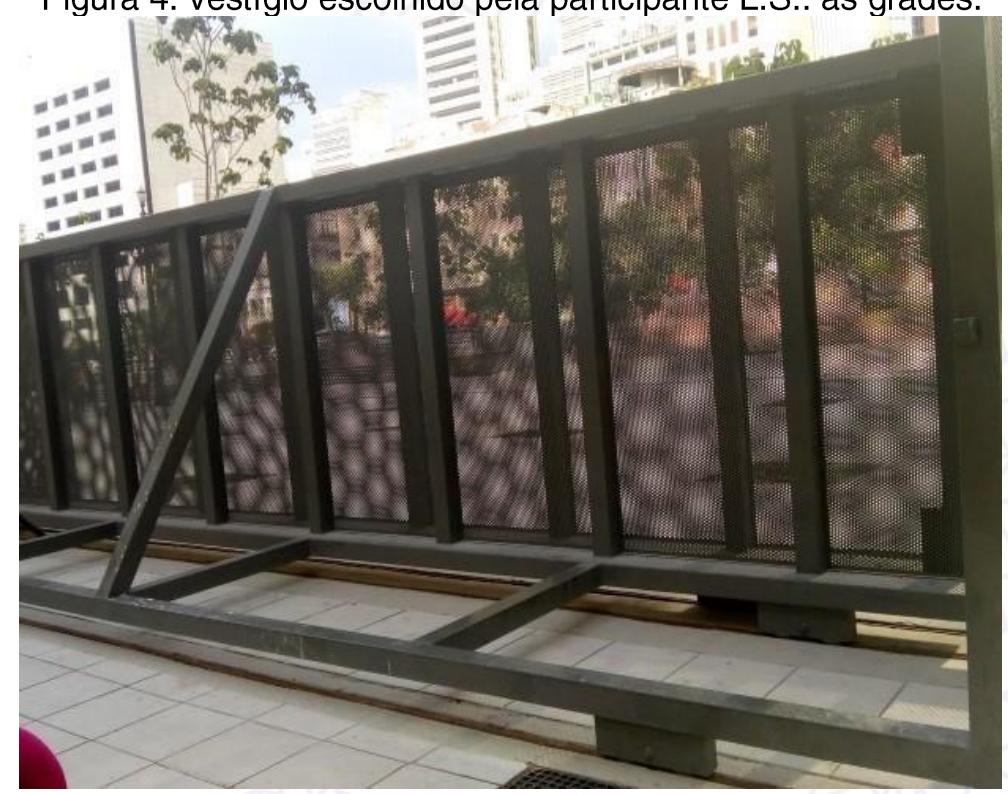

Fonte: acervo pessoal da pesquisadora. 
É relevante ressaltar a percepção crítica de W.M. e L.S. ao refletirem sobre a relação das construções antigas e recentes e de como as pessoas, apesar de circularem pelo centro da cidade, estão à margem da sociedade.

\begin{abstract}
Este mesmo olhar me fez perceber como o velho e o novo convivem, disputam e moldam o mesmo espaço: no centro especificamente prédios antigos acotovelam-se com novos formando uma arquitetura da memória. (WM)

Escolhi aquela palavra porque apesar de ter andado pelo centro de São Paulo, eu vi que esse lugar é preenchido pela margem. (LS)
\end{abstract}

Como último registro, os participantes produziram desenhos. 0 participante WM (figura 5) apresentou sua leitura do Vale do Anhangabaú da seguinte maneira:

as cores e formas representadas simbolizam as camadas naturais e históricas que existem nesse espaço; a cor azul seria o rio Anhangabaú soterrado; cor marrom a terra; cor vermelha o sangue; cor preta o concreto, por fim, os prédios cerram o horizonte e não é possível ver o céu.

No verso do desenho é encontrado este texto que evidencia a percepção de WM: "concreto que destrói as coisas belas, sangue derramado nesta terra, terra que cobre os rios, mas ainda é vida, rios soterrados, pura vida correndo debaixo de nós".

Figura 5: Desenho do participante W.M.

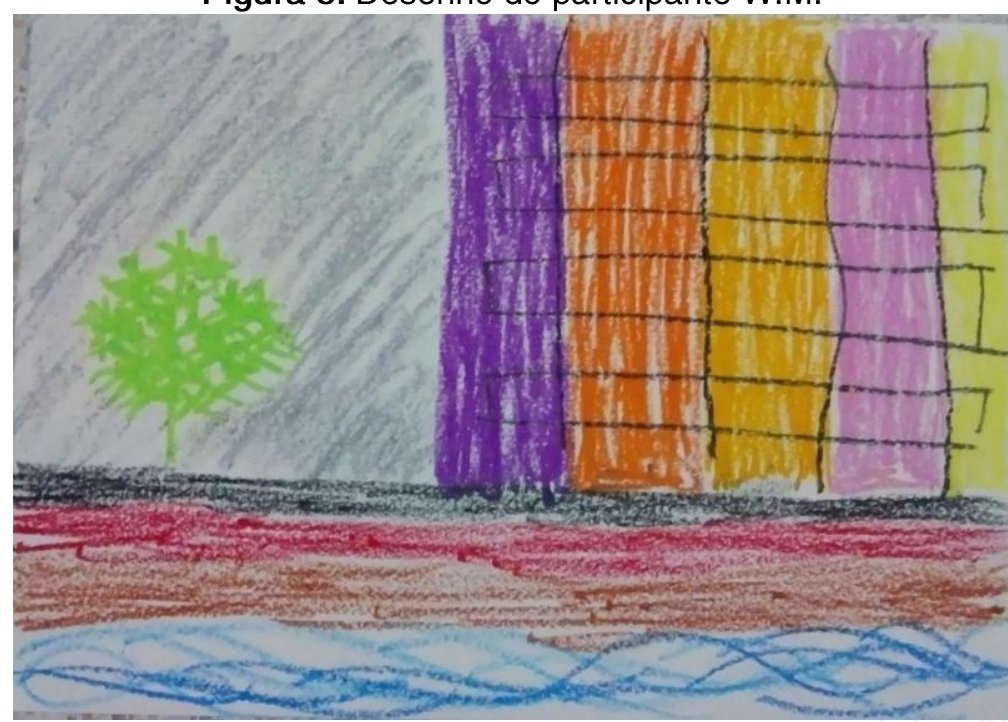

Fonte acervo pessoal da pesquisadora. 
Na roda de conversa, a participante L.S, discorrendo sobre o tempo, comenta sobre a representação do sol como um relógio em seu desenho (figura 6), bem acima da cidade e das pessoas, influenciando-as.

Figura 6: Desenho da participante L.S.

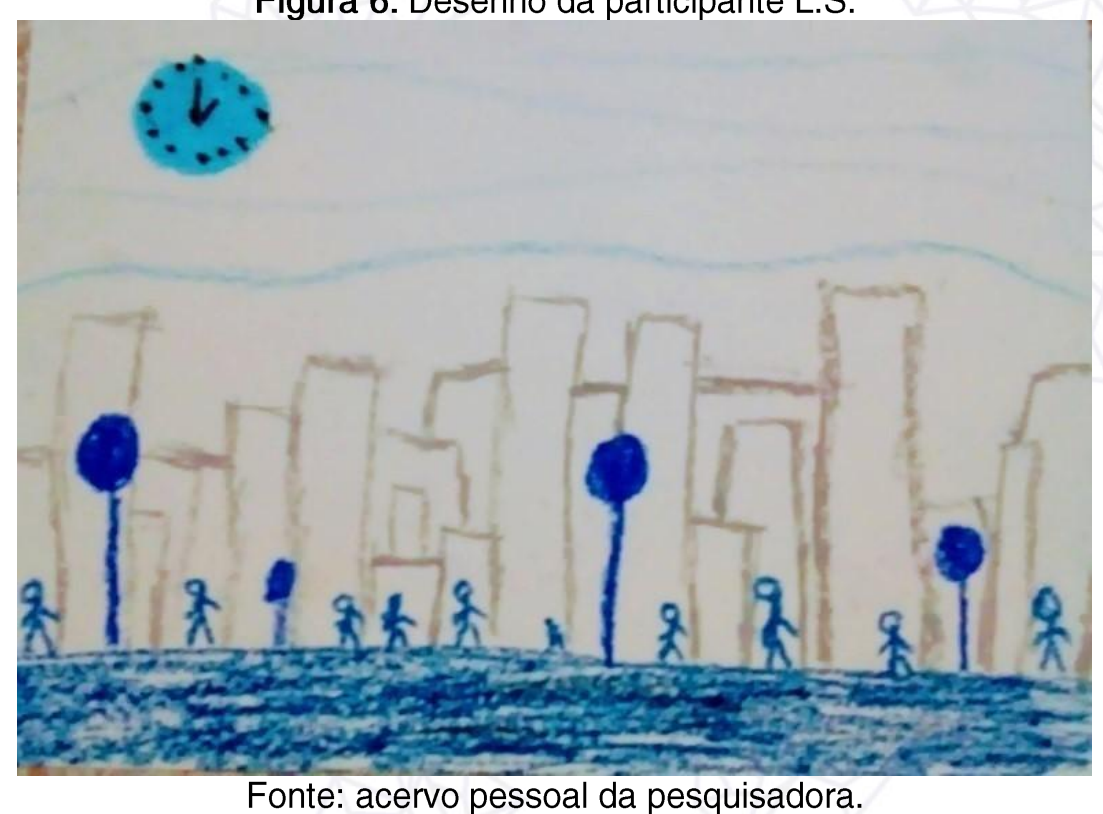

$\mathrm{Na}$ etapa final desta pesquisa, como um desdobramento do Programa Performativo, a pesquisadora elaborou uma Intervenção Instalativa, realizada no mesmo local onde a experiência aconteceu, com o objetivo de criar um elo entre a experiência dela e os registros dos participantes neste processo. Tais registros foram fontes fundamentais na elaboração dessa intervenção sendo que os vestígios, as experiências e reflexões relatados e ilustrados acima serviram como ponto de partida dessa criação. É importante ressaltar que o conceito de Site Specificity ${ }^{3}$ foi aplicado nessa criação.

A Figura 7 retrata o encontro entre a pesquisadora e a transeunte $C$ no decorrer do Programa Performativo. C inicia um diálogo e, nesta breve conversa, relata que recolhe latinhas como meio de sobrevivência e, que nos momentos livres, transitava pelo Vale do Anhangabaú. A ação de recolher o espelho utilizado no Programa Performativo, realizada por $C$ é captada pela pesquisadora e foi o catalisador da criação da referida Intervenção Instalativa.

\footnotetext{
${ }^{3} \mathrm{O}$ termo Site-Specificity refere-se a "uma arte desenvolvida tendo em vista um lugar específico, seja tendo como referência um espaço arquitetônico formal, o meio urbano ou um espaço ambiental natural como uma floresta" (ALMEIDA,2017, p. 45)
} 
Vale ainda destacar que o espelho foi utilizado como um disparador de experiências singulares, possibilitando que os transeuntes observem não só a si mesmos, mas também alguns fragmentos imagéticos da cidade. Neste objeto estava escrito a palavra SOBREVIDA, uma escolha da pesquisadora a partir da observação das transformações constantes que o centro de São Paulo vem atravessando, em específico as obras de requalificação do Vale do Anhangabaú que se iniciaram em $2019^{4}$.

Figura 7: A transeunte $\mathrm{C}$ recolhe o espelho utilizado no Programa Performativo.

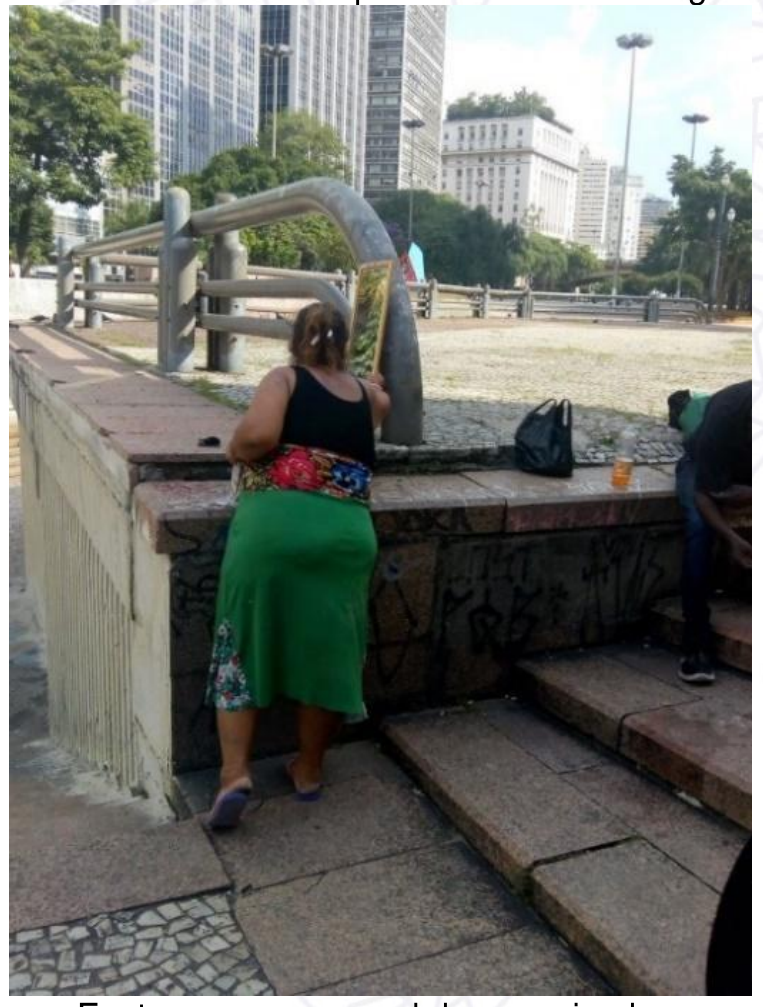

Fonte: acervo pessoal da pesquisadora.

Já os vestígios (figura 8) recolhidos pela pesquisadora através da prática da Deriva como estudo para a instalação neste ambiente, são provenientes das obras de reforma dos locais visitados e foram ressignificados para integrar a Intervenção Instalativa (figura 9). As palavras escritas nestes vestígios foram retiradas dos textos produzidos pelos participantes do Programa Performativo.

\footnotetext{
${ }^{4}$ Disponível em: http://www.capital.sp.gov.br/noticia/prefeitura-inicia-obras-de-requalificacao-dovale-anhangabau\#
} 
Figura 8: Vestígios recolhidos e ressignificados pela pesquisadora.

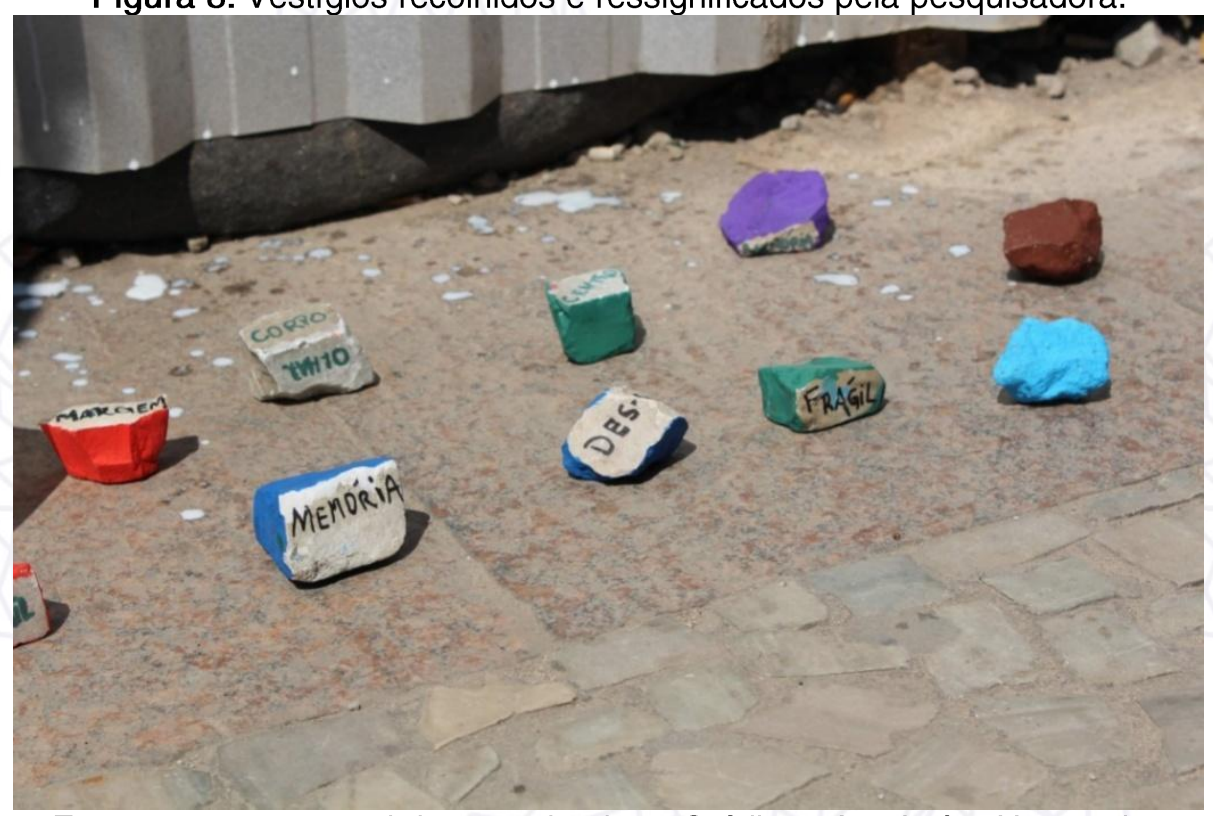

Fonte: acervo pessoal da pesquisadora. Créditos: Ana Luísa Hernandez

A Intervenção Instalativa (Figura 9) buscou sintetizar as experiências propostas nesta pesquisa e assim perceber outras existências na textura urbana em constante modificação. Esta Intervenção buscou também encontrar, na arte, meios para que o corpo-transeunte possa romper sua docilidade diante do poder, criando outras relações com a cidade e produzindo novos sentidos para os lugares que atravessa e que são atravessados por vivências e construções afetivas.

Figura 9: Transeuntes em relação com a Intervenção Instalativa.

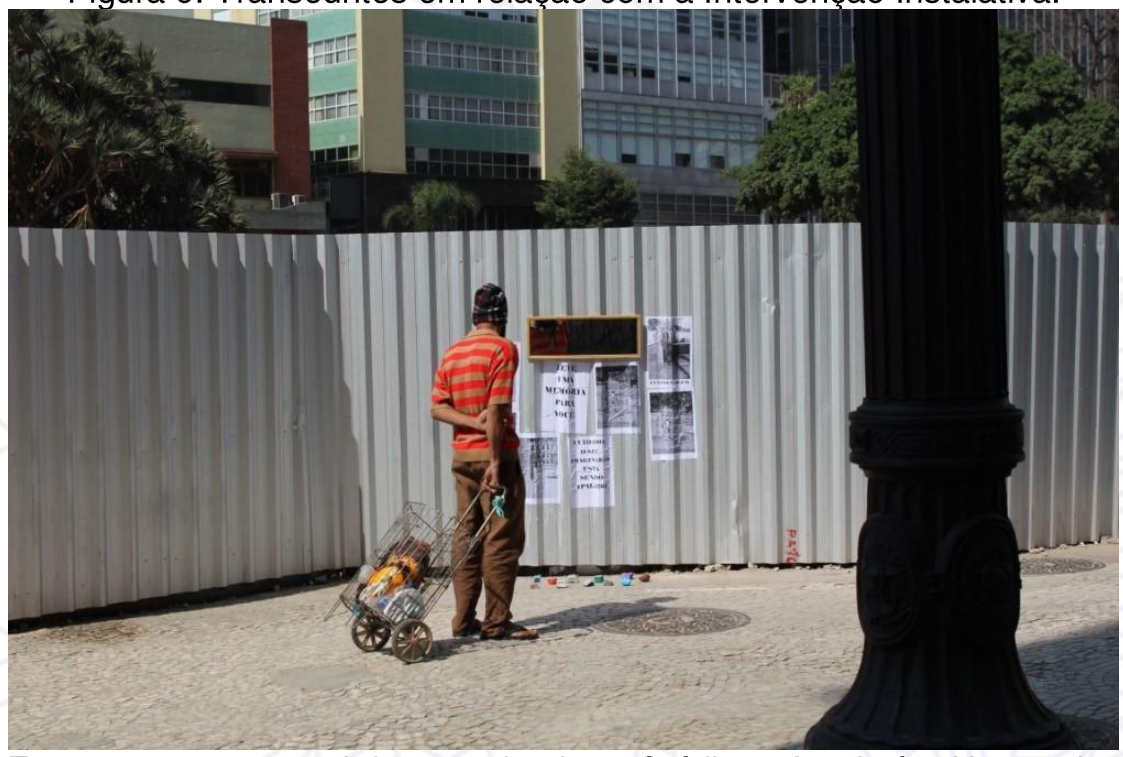

Fonte: acervo pessoal da pesquisadora. Créditos: Ana Luísa Hernandez 


\section{CONSIDERAÇÕES FINAIS}

Através da hipótese investigada, esta pesquisa pôde propiciar, aos participantes e à pesquisadora, a percepção de novas relações afetivas no espaço urbano. O Programa Performativo foi um condutor essencial para a experiência, pois permitiu uma organização dos modos de criação artística, o que viabilizou a execução dos experimentos práticos. Dessa forma, a Deriva realizada pelos participantes foi geradora da Intervenção Instalativa, realizada pela pesquisadora.

A experiência, ao constituir a relação entre corpo, arte e cidade, deflagra diversos aspectos sociais e políticos que atravessam o sujeito contemporâneo. Este fato evidencia a necessidade da proposição de práticas artísticas no espaço-público que conduzam o indivíduo a transformar, mesmo que efemeramente, a relação do seu corpo e suas subjetividades com a cidade.

A Intervenção Instalativa sofreu alterações no seu planejamento inicial devido as obras de requalificação do Vale do Anhangabaú sendo necessária uma reelaboração a partir da nova configuração espacial. Esta Intervenção buscou ressignificar a materialidade daquele espaço para propor uma reflexão crítica sobre a efemeridade da cidade e sua memória histórica e social. Por fim, estes experimentos pretendem também, como desdobramento desejável, fomentar futuras pesquisas que utilizem a cidade como espaço e fonte de criações artísticas.

\section{Referências bibliográficas}

ALMEIDA, Renato Barros. Memória, Vestígio e alienação: relações entre o objeto e a cidade. 2017. Dissertação (Mestrado em Artes Visuais) - Programa de Pós-Graduação em Artes Visuais do Instituto de Artes da Universidade Estadual de Campinas, 2017. 
ARANTES, Antonio A. et al. A guerra dos lugares: sobre fronteiras simbólicas e liminaridades no espaço urbano. Revista de Patrimônio Histórico e Artístico Nacional, v. 2, p. 190-203, 1994.

DEBORD, Guy. Teoria da Deriva. Texto publicado no n. 2 da Internacional Situacionista, dezembro de 1958. Tradução de Amélia Luisa Damiami. Disponível em:

<http://www.geografia.fflch.usp.br/graduacao/apoio/Apoio/Apoio_Fani/flg0560/2010/ Teoria_da_Deriva.pdf $>$.Acesso em: 20. Abril. 2018.

FABIAO, Eleonora Batista. Programa Performativo: O Corpo - em - experiência. ILINX Revista do LUME, Núcleo interdisciplinar de Pesquisas Teatrais - UNICAMP. Brasil, n.4, dez. 2013. Disponível em: <https://www.cocen.unicamp.br/revistadigital/index.php/lume/article/view/276>. Ace sso em: 24. Abril. 2018. ISSN: 2316-8366

PRAÇA das Artes. In: ENCICLOPÉDIA Itaú Cultural de Arte e Cultura Brasileiras. São Paulo: Itaú Cultural, 2020. Disponível em:

<http://enciclopedia.itaucultural.org.br/obra69952/praca-das-artes>. Acesso em: 01 de Jun. 2020. Verbete da Enciclopédia.

ISBN: 978-85-7979-060-7

Prefeitura inicia obras de requalificação do Vale do Anhangabaú. Prefeitura de São Paulo_Prefeitura.2019. Disponível em:

<http://www.capital.sp.gov.br/noticia/prefeitura-inicia-obras-de-requalificacao-dovale-anhangabau\#:>. Acesso em: 24 de julho de 2019. 